\title{
Thirty-day VARC-2 and performance data of a new self- expanding transcatheter aortic heart valve
}

\author{
Hendrik Treede ${ }^{*}$, MD; Edith Lubos², MD; Lenard Conradi ${ }^{1}$, MD; Florian Deuschl${ }^{2}$, MD; \\ Federico M. Asch ${ }^{3}$, MD; Neil J. Weissman ${ }^{3}$, MD; Niklas Schofer ${ }^{2}$, MD; Johannes Schirmer ${ }^{1}$, MD; \\ Dietmar Koschyk², MD; Stefan Blankenberg ${ }^{2}$, MD; Hermann Reichenspurner ${ }^{1}, \mathrm{MD}, \mathrm{PhD}$; Ulrich Schaefer ${ }^{2}$, MD \\ 1. Department of Cardiovascular Surgery, University Heart Center Hamburg, Hamburg, Germany; 2. Department of General \\ and Interventional Cardiology, University Heart Center Hamburg, Hamburg, Germany; 3. MedStar Cardiovascular Research \\ Network at Washington Hospital Center, Washington, DC, USA
}

This paper also includes supplementary data published online at: http://www.pcronline.com/eurointervention/90th_issue/160

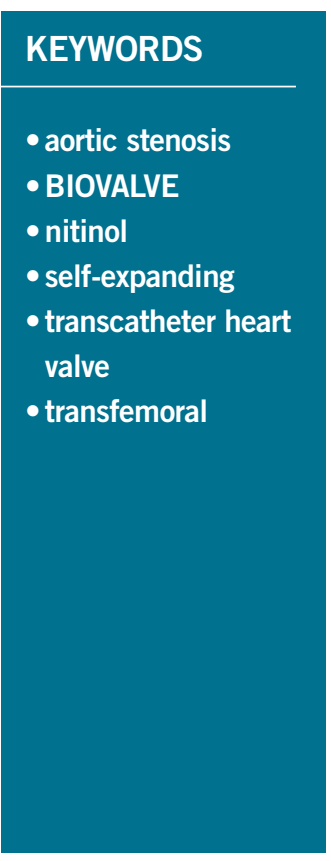

\section{Abstract}

Aims: Transcatheter aortic valve therapy has become an established procedure for patients at high risk for surgical valve replacement. The BIOVALVE-I study aims to assess the safety and performance of a novel self-expanding transcatheter heart valve.

Methods and results: In this prospective, single-centre, first-in-human study, 13 patients with severe aortic stenosis suitable for transfemoral transcatheter aortic valve implantation were enrolled. Mean logistic EuroSCORE was $14.4 \pm 3.7 \%$ and mean STS PROM score was $4.3 \pm 1.6 \%$. The primary endpoint, 30-day early safety composite per VARC-2, was observed in two patients $(15.4 \%$, one life-threatening bleeding and one valve-in-valve procedure). The implant was aborted in two patients due to unsuitable aortic anatomy. Overall, device success was obtained in nine patients $(69.2 \%$, two aborted implants, one valve-in-valve procedure and one patient with moderate aortic regurgitation). As determined by an independent core laboratory, all but one patient had less than moderate total aortic regurgitation at 30-day follow-up, mean aortic gradient was $6.7 \pm 2.3 \mathrm{mmHg}$ and effective orifice area $1.8 \pm 0.3 \mathrm{~cm}^{2}$. Pacemakers were implanted in three patients (23.1\%), and no death, stroke, myocardial infarction or acute kidney failure was observed.

Conclusions: In this first-in-human study, the feasibility of implantation of the BIOVALVE system and its re-sheathing functionality was demonstrated, and short-term safety data were encouraging. Larger studies are required to confirm the performance of the device.

*Corresponding author: Department of Cardiovascular Surgery, University Heart Center Hamburg, Martinistr. 52, 20246 


\section{Abbreviations}

$\begin{array}{ll}\text { ASA } & \text { American Society of Anesthesiologists } \\ \text { AS } & \text { aortic stenosis } \\ \text { EOA } & \text { effective orifice area } \\ \text { LBBB } & \text { left bundle branch block } \\ \text { NIHSS } & \text { National Institute of Health Stroke Scale } \\ \text { NYHA } & \text { New York Heart Association } \\ \text { STS PROM } & \text { Society of Thoracic Surgeons Predicted Risk of } \\ & \text { Mortality } \\ \text { TAVI } & \text { transcatheter aortic valve implantation } \\ \text { VARC } & \text { Valve Academic Research Consortium }\end{array}$

\section{Introduction}

Calcific aortic stenosis (AS) is the most frequent heart valve disease in Europe and North America. It increases with age and has a prevalence of $2-7 \%$ of the population beyond 65 years $^{1}$. There is a consensus that early intervention should be performed in subjects with severe, symptomatic $\mathrm{AS}^{1}$. However, Iung et $\mathrm{al}^{2}$ demonstrated that surgery was denied, or patients were not referred for surgical assessment, in one third of elderly subjects with severe symptomatic AS. Transcatheter heart valve implantation (TAVI) has been developed as an alternative to surgical aortic valve replacement for this high-risk subject population.

The first human implant of a transcatheter heart valve was conducted in 2002. In 2007 CE certification was obtained for the CoreValve (Medtronic, Minneapolis, MN, USA) and SAPIEN (Edwards Lifesciences, Irvine, CA, USA) transcatheter heart valves. Since then, TAVI has proven to be feasible and safe in several studies and registries and has become an established procedure ${ }^{3}$.

Meanwhile, several next-generation and novel TAVI devices have been tested in clinical studies and have gained CE mark approval ${ }^{4,5}$. The BIOVALVE transcatheter aortic valve system (Biotronik AG, Bülach, Switzerland) is a novel device designed to offer specific features such as (a) ability to re-sheath the valve, (b) stent design to allow an easier stent placement and a uniform radial force for the indicated annulus diameter range, (c) larger stent cell size in the outflow tract allowing unrestricted access to the coronary arteries, and (d) ease of use in device handling and implantation with only one component on the handle to place, re-sheath and release the valve. The aim of the BIOVALVE-I first-in-human study is to assess the safety and performance of this novel transcatheter heart valve.

\section{Methods STUDY DESIGN AND POPULATION}

BIOVALVE-I is a prospective, single-centre, first-in-human study to evaluate the safety and clinical performance of the BIOVALVE aortic bioprosthesis in subjects with severe symptomatic aortic valve stenosis, who are - as judged by the Heart Team - indicated for transfemoral transcatheter aortic valve implantation as suggested by the European Society of Cardiology (ESC) guidelines ${ }^{1}$.

The study is registered at ClinicalTrials.gov (NCT02249000) where the full set of inclusion and exclusion criteria is available.
Relevant medical inclusion criteria were NHYA Class $\geq$ II, high surgical risk: logistic EuroSCORE-I $\geq 20 \%$ (or EuroSCORE-II equivalent) or Society of Thoracic Surgeons Predicted Risks of Mortality (STS PROM) score $\geq 10 \%$ or comorbidity judged by the Heart Team (consisting of at least one interventional cardiologist and one cardiovascular surgeon) to pose an absolute or relative contraindication for conventional aortic valve replacement, severe symptomatic calcific AS characterised by mean aortic gradient $>40 \mathrm{mmHg}$ or peak jet velocity $>4.0 \mathrm{~m} / \mathrm{s}$ or effective orifice area (EOA) of $<1.0 \mathrm{~cm}^{2}$, and an annulus diameter by multislice computed tomography from 23 to $26 \mathrm{~mm}$ for the size M (medium, $29 \mathrm{~mm}$ ) prosthesis. Relevant medical exclusion criteria were congenital bicuspid or unicuspid valve, prosthetic mitral valve, extreme tortuosity of the aortic arch, thoracic or abdominal aortic aneurysm, presence of endovascular stent graft, left ventricular outflow tract obstruction such as hypertrophic obstructive cardiomyopathy or subject presenting with systolic anterior motion of mitral valve leaflets, evidence of intracardiac mass, thrombus or vegetation, access vessel characteristics that would preclude safe placement of an $18 \mathrm{Fr}$ sheath, vessel characteristics that would preclude safe delivery of the BIOVALVE prosthesis to the ascending aorta, severe mitral regurgitation grade $>3$, severe mitral stenosis, severe left ventricular dysfunction with left ventricular ejection fraction $<20 \%$, planned percutaneous coronary intervention during the same intervention, emergency surgery procedures within 30 days prior to the intervention, renal insufficiency (creatinine $>2.5 \mathrm{mg} / \mathrm{dl}$ ) or subject under dialysis and/or renal replacement therapy, evidence of acute myocardial infarction $\leq 30$ days prior to procedure, ongoing sepsis or suspected active endocarditis.

The intervention should follow standard TAVI practice, and medical treatment was left to the discretion of the treating investigator. Clinical and echocardiographic follow-up has been scheduled at one, six and 12 months and annually thereafter up to five years, with telephone follow-up at three months. NIHSS (National Institute of Health Stroke Scale) assessment was required to detect potential neurological deficits.

The study is conducted according to the Declaration of Helsinki, ICH-GCP, and ISO 14155:2011, and approved by the respective institutional ethical committees. All patients provided written informed consent prior to any study procedure. Monitoring includes $100 \%$ source document verification. Echocardiographic analysis is performed by an independent core laboratory (MedStar Cardiovascular Research Network, Washington Hospital Center, Washington, DC, USA), and the study is supervised by an independent data safety monitoring committee, consisting of a data safety monitoring board and a clinical events committee which will adjudicate all adverse events as well as VARC-1 and VARC-2 composites $^{6,7}$.

\section{STUDY DEVICE}

The BIOVALVE system is intended to be implanted in patients with severe symptomatic calcified stenosis of the native aortic valve at high risk for surgical aortic valve replacement. It consists of three components, the prosthesis, the loading device and the delivery system (Figure 1). 

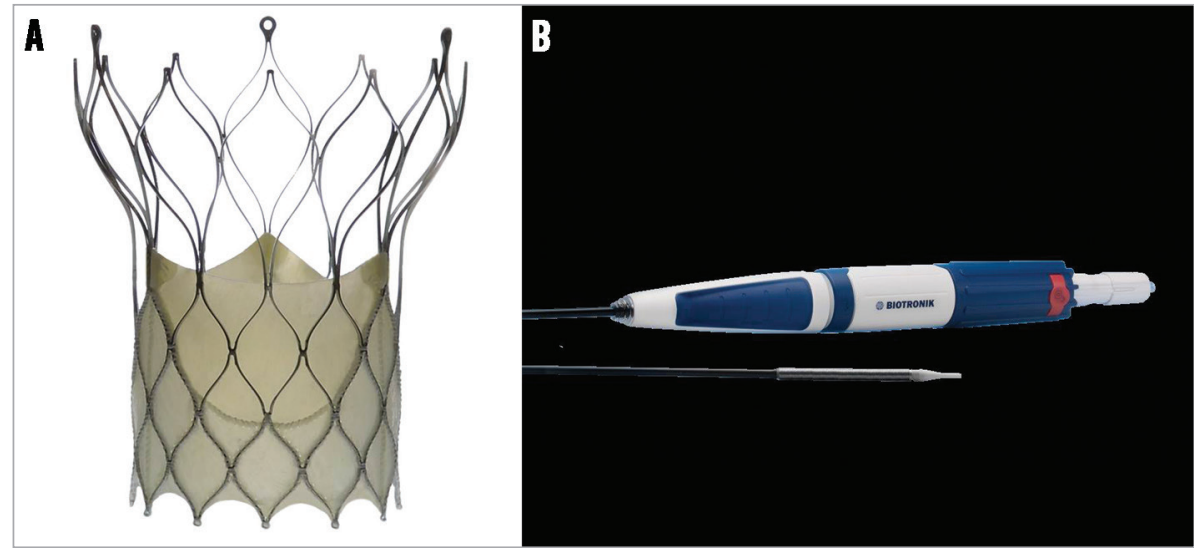

Figure 1. BIOVALVE bioprosthesis system. A) BIOVALVE prosthesis; B) handle and tip of delivery system.

The prosthetic valve is made from porcine pericardium and consists of a skirt (constituting the sealing zone) and three leaflets sutured onto the stent frame in a trileaflet configuration. The prosthesis features a supra-annular valve design to allow a large effective orifice area. The expansion force of the prosthesis varies over the length of the stent and correlates with the length of the rhombi. The outflow has the longest cells, and has, therefore, the least amount of expansion force as it only orients the stent axially. The middle section below the commissure has medium expansion force. The highest expansion force is where it is needed most, at the inflow end, where the stent struts appose to the vessel wall and, together with the attached tissue, provide adequate sealing. In brief, the high radial force at the inflow section in combination with the longitudinal flexibility supports fast and correct anchoring of the prosthesis in the initial phase of the release, whereas the reduced resistance in the outflow section still provides some flexibility in the stent to follow the curvature of the ascending aorta. The wider outflow end of the stent is equipped with three eyelets arranged with a spacing of 120 degrees. Eyelets firmly attach the prosthesis to the delivery system. The 18 Fr distal end of the delivery system is a moveable sheath that keeps the prosthesis in a crimped condition. A radiopaque marker ring is located close to the distal end of the capsule, and the catheter tip is radiopaque and atraumatic. The prosthesis is currently available in size M (medium, $29 \mathrm{~mm}$ ) to accommodate annulus diameters of $23 \mathrm{~mm}$ to $26 \mathrm{~mm}$. Additional sizes are under development.

The BIOVALVE is designed for transfemoral access and implantation is controlled through an ergonomic handle which provides direct response throughout the entire procedure. In the first step, the prosthesis is deployed up to the re-sheathing limit (approximately $80 \%$ of full release) with a targeted implant depth of $6 \mathrm{~mm}$ below the annulus. At this point, sufficient valve function is given and positioning of the prosthesis can be calmly assessed. In case of suboptimal positioning, the prosthesis can be re-sheathed, repositioned and redeployed. Final release is initiated by pressing the safety buttons and releasing the prosthesis fully from the delivery system. The implantation of the BIOVALVE prosthesis and the re-sheathing mechanism are shown in Moving image 1 and Moving image 2.

\section{ENDPOINTS AND DEFINITIONS}

The primary endpoint is "early safety" at 30 days according to the Valve Academic Research Consortium-2 criteria (VARC-2) a composite of all-cause mortality, all stroke (disabling/non-disabling), life-threatening bleeding, acute kidney injury stage 2 or 3 (including renal replacement therapy), coronary artery obstruction requiring intervention, major vascular complication and valverelated dysfunction requiring repeat procedure. Secondary endpoints at 30 days are "early safety" as per VARC- 1 , as well as life-threatening bleeding, acute kidney injury, coronary obstruction requiring intervention, major vascular complication, valve-related dysfunction requiring repeat procedure, periprocedural myocardial infarction, hospitalisation for valve-related symptoms or worsening of congestive heart failure as per VARC-2 criteria $^{6}$.

In addition, NYHA Class III or IV, conduction disturbances and arrhythmias, device success per VARC- $2^{6}$, and echocardiographic parameters at discharge and 30 days (EOA, EOA Index, mean prosthetic valve gradient, prosthetic valve regurgitation) were evaluated. Severity of prosthetic valve regurgitation was graded on a seven-point scale (none, trace, mild, mild-moderate, moderate, moderate to severe, severe) following a multi-window, multiparametric approach which included pressure half time, jet area ratio, jet diameter ratio, diastolic flow reversal and \% of valve circumference ${ }^{8}$.

\section{STATISTICAL ANALYSIS}

Statistical analyses were performed based on available data for patients in whom the implant was attempted (intention-to-treat analysis). Patients not receiving a BIOVALVE were included in clinical, but excluded from echocardiographic follow-up.

Data are presented using descriptive statistical methods. For quantitative variables, mean values and standard deviation, as well as the $95 \%$ confidence interval (CI) for the mean, when relevant, are calculated. For qualitative variables, absolute and relative frequencies are determined. A p-value of $<0.05$ was deemed to be statistically significant. All statistical analyses were carried out using SAS 9.3 (SAS Institute Inc., Cary, NC, USA). 


\section{Results \\ BASELINE CHARACTERISTICS}

Baseline characteristics are detailed in Table 1. The mean age was $83.3 \pm 6.3$ years, all patients were in NYHA Class III and suffered from hypertension, and one quarter additionally suffered from coronary artery disease, diabetes mellitus, and anaemia. The mean logistic EuroSCORE was $14.4 \pm 3.7 \%$ and the mean STS PROM score was $4.3 \pm 1.6 \%$. The EOA was $0.7 \pm 0.2 \mathrm{~cm}^{2}$, the mean gradient was $42.1 \pm 7.0 \mathrm{mmHg}$, and two patients $(15.4 \%)$ had moderate total aortic regurgitation.

\section{PROCEDURAL CHARACTERISTICS}

Details of the implantation of the first patient enrolled in BIOVALVE-I are provided in Figure $\mathbf{2}$ and of the last patient enrolled in Figure $\mathbf{3}$ and Moving image 2. In two patients the implant was aborted because

Table 1. Demographics and baseline characteristics.

\begin{tabular}{|c|c|c|}
\hline \multicolumn{2}{|l|}{ 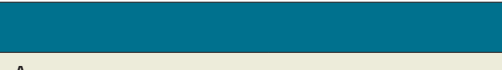 } & $n=13$ \\
\hline \multicolumn{2}{|l|}{ Age, years } & $83.3 \pm 6.3[79.5,87.1]$ \\
\hline \multicolumn{2}{|c|}{ Body mass index, $\mathrm{kg} / \mathrm{m}^{2}$} & $26.1 \pm 4.6$ \\
\hline \multicolumn{2}{|l|}{ Female } & $8(61.5 \%)$ \\
\hline \multicolumn{2}{|l|}{ Diabetes mellitus } & $3(23.1 \%)$ \\
\hline \multicolumn{2}{|l|}{ COPD } & $2(15.4 \%)$ \\
\hline \multicolumn{2}{|l|}{ Current anaemia } & $3(23.1)$ \\
\hline \multicolumn{2}{|l|}{ Renal insufficiency } & $13(100.0 \%)$ \\
\hline \multicolumn{2}{|c|}{ Stage 1 (GFR: $>90 \mathrm{ml} / \mathrm{min} / 1.73 \mathrm{~m}^{2}$ ) } & $1(7.7 \%)$ \\
\hline \multicolumn{2}{|c|}{ Stage 2 (GFR: $60-89 \mathrm{ml} / \mathrm{min} / 1.73 \mathrm{~m}^{2}$ ) } & $8(61.5 \%)$ \\
\hline \multicolumn{2}{|c|}{ Stage 3 (GFR: $30-59 \mathrm{ml} / \mathrm{min} / 1.73 \mathrm{~m}^{2}$ ) } & $4(30.8 \%)$ \\
\hline \multicolumn{2}{|l|}{ Current cancer } & $2(15.4 \%)$ \\
\hline \multicolumn{2}{|l|}{ Hypertension } & $13(100.0 \%)$ \\
\hline \multicolumn{2}{|l|}{ Hyperlipidaemia } & $3(23.1 \%)$ \\
\hline \multicolumn{2}{|c|}{ Coronary artery disease } & $3(23.1 \%)$ \\
\hline \multicolumn{2}{|c|}{ Prior coronary artery bypass graft } & $1(7.7 \%)$ \\
\hline \multicolumn{2}{|l|}{ Carotid disease } & $1(7.7 \%)$ \\
\hline \multicolumn{2}{|c|}{ Peripheral artery disease } & $2(15.4 \%)$ \\
\hline \multicolumn{2}{|c|}{ Cerebrovascular event* } & $2(15.4 \%)$ \\
\hline \multicolumn{2}{|l|}{ Porcelain aorta } & $0(0.0 \%)$ \\
\hline \multicolumn{2}{|l|}{ Pacemaker implant } & $1(7.7 \%)$ \\
\hline \multicolumn{2}{|c|}{ Logistic EuroSCORE-I, \% } & $14.4 \pm 3.7[12.1,16.6]$ \\
\hline \multicolumn{2}{|c|}{ STS PROM score, \% } & $4.3 \pm 1.6[3.3,5.2]$ \\
\hline NYHA class & III & $13(100.0 \%)$ \\
\hline \multirow[t]{3}{*}{ ASA classification } & 2 & $1(7.7 \%)$ \\
\hline & 3 & $10(76.9 \%)$ \\
\hline & 4 & $2(15.4 \%)$ \\
\hline \multirow[t]{2}{*}{ NIHSS score } & 0 & $12(92.3 \%)$ \\
\hline & $1-4$ & $1(7.7 \%)$ \\
\hline
\end{tabular}

Data are displayed as mean \pm SD $[95 \% \mathrm{Cl}]$ or $\mathrm{n}(\%)$. *One stroke, one transient ischaemic attack. ASA: American Society of Anesthesiologists COPD: chronic obstructive pulmonary disease; LCA: left coronary artery; NIHSS: National Institute of Health Stroke Scale; NYHA: New York Heart Association; RCA: right coronary artery; STS PROM: Society of Thoracic Surgeons Predicted Risk of Mortality

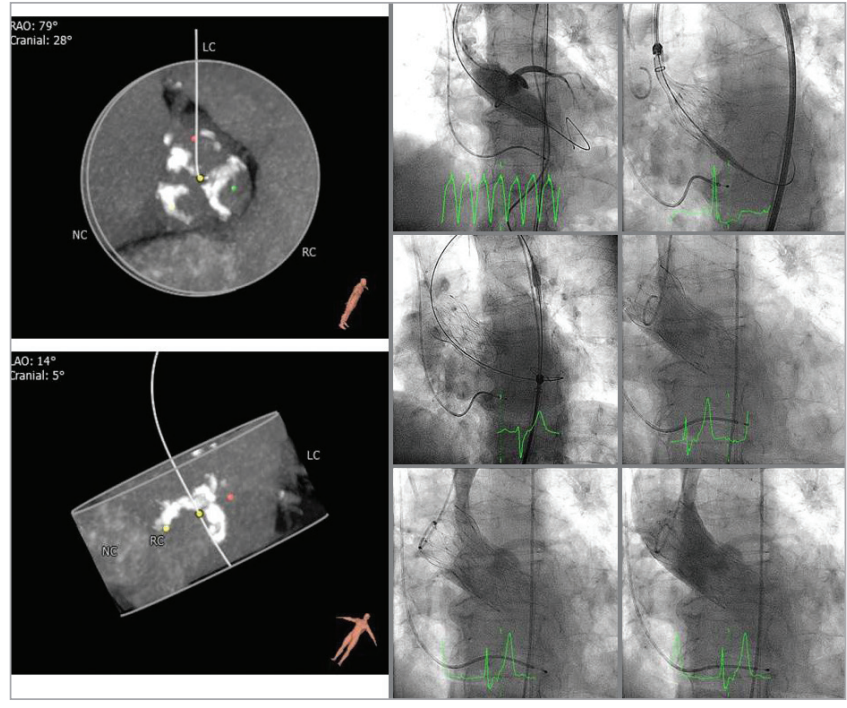

Figure 2. First patient implanted with the BIOVALVE. Echo measurements: severe aortic valve calcification (including left ventricular outflow tract) with severely reduced mobility, peak and mean aortic gradient 104.1 and $67.9 \mathrm{mmHg}$, effective orifice area (EOA) $0.44 \mathrm{~cm}^{2}$. CT measurements: distance RCA/LCA ostia 13.6/11.7 mm. Annulus min/max diameter 20.7/25.8 mm, annulus diameter (arealperimeter derived) 23.5/24.0 mm. 30-day echo data: peak and mean aortic gradient 21.0 and $10.5 \mathrm{mmHg}, E O A 1.41 \mathrm{~cm}^{2}$, aortic regurgitation $1+$.

intraprocedurally the anatomy was deemed unsuitable for implantation of a self-expanding valve (horizontal aorta). Both patients received a $26 \mathrm{~mm}$ balloon-expandable valve and had an uneventful postoperative course except for the occurrence of left bundle branch blocks (LBBB), which was observed in one patient on the day of procedure and in another one at day two. In 11 patients (84.6\%), the BIOVALVE was implanted. Of these, one patient had severe aortic insufficiency which could not be resolved after two post-dilatations. This patient was then successfully treated with a valve-in-valve implantation using a $26 \mathrm{~mm}$ balloon-expandable valve with good haemodynamic results and an uneventful postoperative course. Overall, re-sheathing was performed in five patients (38.5\%) (single re-sheathing in two, more

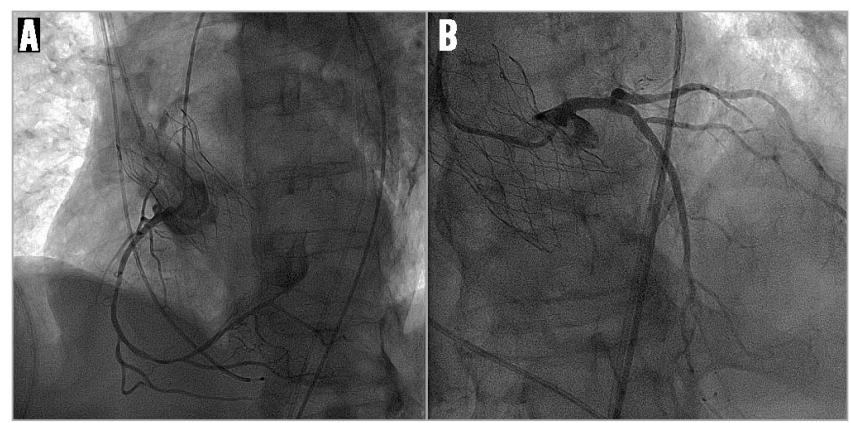

Figure 3. Access to coronary arteries after implantation of the BIOVALVE prosthesis. A) Right coronary artery. B) Left coronary artery. 
than one re-sheathing in three patients). When implanted, the prosthesis could be placed at the targeted implant depth in all patients. Device success according to VARC-2 criteria was achieved in nine out of 13 patients $(69.3 \%)$ (two patients with aborted implant in which a balloon-expandable valve was deemed more appropriate, one patient with valve-in-valve implantation and one patient with moderate aortic regurgitation at 30 days). Further procedural details are depicted in Table 2 and Table 3.

\section{0-DAY FOLLOW-UP}

Clinical follow-up was performed in all patients and echocardiographic follow-up in eight patients. After BIOVALVE implantation, NYHA class had improved in seven out of nine patients, was unchanged in one and worsened in one (Figure 4). The latter

Table 2. Procedure details.

\begin{tabular}{|l|c|}
\hline & $\mathbf{n = 1 3}$ \\
\hline General anaesthesia & $13(100.0 \%)$ \\
\hline Predilatation & $13(100.0 \%)$ \\
\hline Deployment under rapid pacing & $11(84.6 \%)$ \\
\hline Pacing rate deployment, bpm & $153.5 \pm 31.3$ \\
\hline Post-dilatation* & $9(81.8 \%)$ \\
\hline \multicolumn{1}{|c|}{ Post-dilatation balloon diameter, $\mathrm{mm}^{2}$} & $23.4 \pm 1.4$ \\
\hline Prosthesis embolisation & $0(0.0 \%)$ \\
\hline Free coronary flow* & $11(100.0 \%)$ \\
\hline $\begin{array}{l}\text { Data are displayed as mean } \pm \text { SD or n/total number of patients }(\%) . \\
\text { *Based on } 11 \text { valves implanted. }\end{array}$ \\
\hline
\end{tabular}

patient was hospitalised for recurrent dyspnoea. The echocardiographic assessment showed good results of the implanted valve. Most likely, the dyspnoea was tachycardia-induced with preexisting atrial fibrillation. The NIHSS score was assessed in nine patients and remained unchanged compared to baseline (only one patient with a score above 0 ). The mean EOA improved from $0.6 \pm 0.3 \mathrm{~cm}^{2}$ to $1.8 \pm 0.3 \mathrm{~cm}^{2}, \mathrm{p}<0.001$, and the mean aortic gradient from $42.1 \pm 17.0 \mathrm{mmHg}$ to $6.7 \pm 2.3 \mathrm{mmHg}, \mathrm{p}<0.001$ (Table 4, Figure 5). One patient had a moderate paravalvular leak at 30 days and no central leakage was observed.

The VARC-2 early safety composite was observed in two patients $(15.4 \%)$ (one life-threatening bleeding and one valve-invalve procedure). No death, stroke, myocardial infarction, major vascular complication, coronary obstruction requiring intervention,

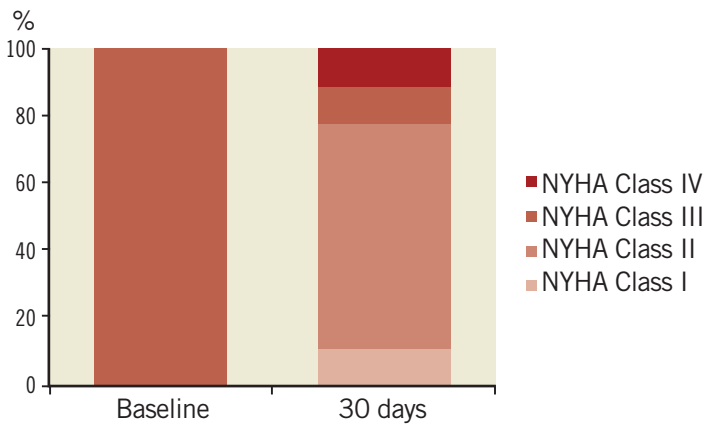

Figure 4. NYHA classification at baseline and 30 days. NYHA class improved in seven patients, remained unchanged in one and worsened in one patient with tachycardia-induced dyspnoea.

Table 3. Baseline and operative characteristics.

\begin{tabular}{|c|c|c|c|c|c|c|c|c|c|c|c|c|c|c|c|c|}
\hline \multirow[b]{2}{*}{$\begin{array}{l}\text { 윰 } \\
\text { 产 } \\
\text { \# }\end{array}$} & \multicolumn{7}{|c|}{ Baseline } & \multirow[b]{2}{*}{ 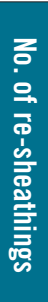 } & \multicolumn{7}{|c|}{ Procedure/Discharge } & \multirow[b]{2}{*}{$\begin{array}{l}\text { 马 } \\
\text { 禀 } \\
\text { 总 }\end{array}$} \\
\hline & $\begin{array}{l}\text { 罩 } \\
\text { 虽 }\end{array}$ & 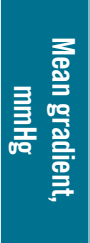 & 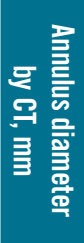 & 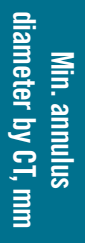 & 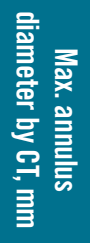 & 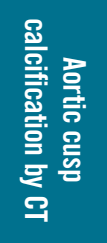 & 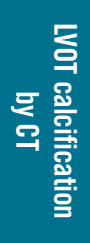 & & 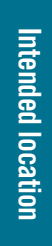 & 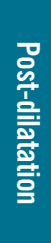 & $\begin{array}{l}\text { 罣 } \\
\text { 올 }\end{array}$ & 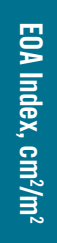 & 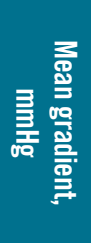 & 俤 & 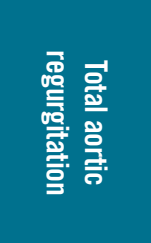 & \\
\hline 1 & 0.44 & 67.9 & 24.0 & 20.7 & 25.8 & Moderate & Severe & 0 & Yes & Yes & 1.47 & 0.9 & 4.7 & 1.73 & Mild & - \\
\hline 2 & 0.49 & 79.1 & 23.3 & 22.4 & 24.3 & Severe & None & 1 & Yes & Yes & 1.90 & 1.3 & 7.7 & 1.88 & Mild-moderate & - \\
\hline 3 & 0.60 & 56.5 & 24.7 & 22.3 & 27.1 & Moderate & None & 2 & - & - & - & - & - & - & - & No implant \\
\hline 4 & 0.68 & 25.5 & 24.3 & 22.5 & 26.1 & Moderate & Mild & 0 & Yes & Yes & 1.86 & 1.0 & 6.6 & 1.65 & Moderate & - \\
\hline 5 & 0.77 & 21.7 & 26.0 & 24.8 & 27.1 & Moderate & None & 2 & Yes & Yes & 2.27 & 1.3 & 3.6 & 1.28 & Trace & - \\
\hline 6 & 0.81 & 34.9 & 24.1 & 19.4 & 27.5 & Moderate & None & 0 & Yes & Yes & 1.92 & 1.1 & 7.8 & 1.96 & Mild & - \\
\hline 7 & 0.62 & 36.7 & 23.0 & 20.5 & 26.0 & Severe & None & 0 & Yes & Yes & 1.88 & 1.2 & 3.5 & 1.40 & Moderate & - \\
\hline 8 & 1.01 & 36.8 & 23.7 & 21.3 & 25.4 & Severe & None & 1 & Yes & № & NAV & NAV & NAV & NAV & NAV & - \\
\hline 9 & 0.68 & 24.4 & 25.2 & 22.6 & 27.0 & Moderate & None & 0 & Yes & № & 1.74 & NAV & 9.4 & 2.09 & Trace & - \\
\hline 10 & 0.58 & 45.3 & 23.2 & 19.3 & 25.7 & Severe & None & 0 & Yes & Yes & 1.68 & NAV & 5.5 & 1.53 & Moderate & - \\
\hline 11 & 0.69 & 32.2 & 24.8 & 22.0 & 28.8 & Mild & None & 2 & - & - & - & - & - & - & - & No implant \\
\hline 12 & NAV & 40.8 & 24.4 & 21.5 & 26.7 & Severe & None & 0 & Yes & Yes & - & - & - & - & - & Valve-in-valve \\
\hline 13 & NAV & NAV & 25.3 & 23.9 & 26.2 & Severe & None & 0 & Yes & Yes & 2.01 & NAV & NAV & NAV & NAV & - \\
\hline
\end{tabular}

CT data were assessed by 3 mensio software. Echocardiographic data were assessed by an independent echo core laboratory. If procedural data were not available, discharge dates were used. CT: computed tomography; EOA: effective orifice area; LVOT: left ventricular outflow tract; NAV: not available yet 
Table 4. Echocardiographic parameters per core laboratory assessment.

\begin{tabular}{|c|c|c|c|c|}
\hline & $\begin{array}{c}\text { Baseline } \\
n=13\end{array}$ & $\begin{array}{c}\text { Discharge } \\
n=10\end{array}$ & $\begin{array}{c}30 \text {-day } \\
n=8\end{array}$ \\
\hline \multicolumn{2}{|c|}{ Effective orifice area, $\mathrm{cm}^{2}$} & $0.6 \pm 0.2$ & $1.9 \pm 0.3$ & $1.8 \pm 0.3$ \\
\hline \multicolumn{2}{|c|}{ Effective orifice area index, $\mathrm{cm}^{2} / \mathrm{m}^{2}$} & $0.4 \pm 0.1$ & $1.1 \pm 0.2$ & $1.1 \pm 0.2$ \\
\hline \multicolumn{2}{|c|}{ Peak aortic gradient, $\mathrm{mmHg}$} & $63.6 \pm 22.6$ & $12.1 \pm 4.9$ & $12.8 \pm 5.0$ \\
\hline \multicolumn{2}{|c|}{ Mean aortic gradient, $\mathrm{mmHg}$} & $42.1 \pm 17.0$ & $6.6 \pm 2.6$ & $6.7 \pm 2.3$ \\
\hline \multicolumn{2}{|l|}{ LVEF, \% } & $56.0 \pm 9.5$ & $64.9 \pm 5.4$ & $58.1 \pm 10.5$ \\
\hline \multirow[t]{7}{*}{ Total AR* } & None (0) & $0(0.0 \%)$ & $0(0.0 \%)$ & $1(12.5 \%)$ \\
\hline & Trivial/Trace (0) & $1(8.3 \%)$ & $2(20.0 \%)$ & $0(0.0 \%)$ \\
\hline & Mild (1+) & $8(66.7 \%)$ & $3(30.0 \%)$ & $4(50.0 \%)$ \\
\hline & Mild to moderate $(1+)$ & $1(8.3 \%)$ & $2(20.0 \%)$ & $2(25.0 \%)$ \\
\hline & Moderate (2+) & $2(16.7 \%)$ & $2(20.0 \%)$ & $1(12.5 \%)$ \\
\hline & Moderate to severe $(3+)$ & $0(0.0 \%)$ & $1(10.0 \%)$ & $0(0.0 \%)$ \\
\hline & Severe $(4+)$ & $0(0.0 \%)$ & $0(0.0 \%)$ & $0(0.0 \%)$ \\
\hline \multicolumn{2}{|c|}{ Paravalvular AR } & NA & & \\
\hline \multicolumn{2}{|c|}{ None $(0)$} & & $0(0.0 \%)$ & $1(12.5 \%)$ \\
\hline \multicolumn{2}{|c|}{ Trivial/Trace (0) } & & $2(20.0 \%)$ & $0(0.0 \%)$ \\
\hline \multicolumn{2}{|c|}{ Mild (1+) } & & $3(30.0 \%)$ & $4(50.0 \%)$ \\
\hline \multicolumn{2}{|c|}{ Mild to moderate $(1+)$} & & $2(20.0 \%)$ & $2(25.0 \%)$ \\
\hline \multicolumn{2}{|c|}{ Moderate (2+) } & & $2(20.0 \%)$ & $1(12.5 \%)$ \\
\hline \multicolumn{2}{|c|}{ Moderate to severe (3+) } & & $1(10.0 \%)$ & $0(0.0 \%)$ \\
\hline \multicolumn{2}{|c|}{ Severe (4+) } & & $0(0.0 \%)$ & $0(0.0 \%)$ \\
\hline
\end{tabular}

Data are displayed as mean \pm SD or $n(\%)$. *Data of one patient not evaluable for total aortic regurgitation at baseline. AR: aortic regurgitation

acute kidney injury, prosthetic valve endocarditis, or prosthetic valve thrombosis occurred. However, there was one life-threatening bleeding and one hospitalisation for congestive heart failure (Table 5). Five patients (38.5\%) experienced an LBBB, and three (23.1\%) pacemakers were implanted, one due to an AV block III after predilatation but before valve implantation, one due to an $\mathrm{AV}$ block III after post-dilatation, and one due to an LBBB and AV block I one day post intervention.

\section{Discussion}

The BIOVALVE-I study provided proof of concept and showed that transcatheter aortic heart valve implantation using the BIOVALVE system is feasible and safe.

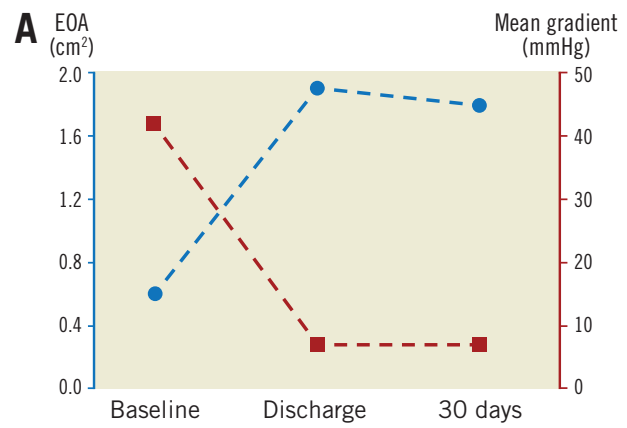

Table 5. Clinical outcomes at $\mathbf{3 0}$ days.

$\mathrm{n}=13$

\begin{tabular}{|l|c|}
\hline Early safety events VARC-2* & $2(15.4 \%)$ \\
\hline Early safety events VARC-1 ${ }^{\top}$ & $2(15.4 \%)$ \\
\hline Death & $0(0.0 \%)$ \\
\hline Stroke, minor and major & $0(0.0 \%)$ \\
\hline Transient ischaemic attack & $0(0.0 \%)$ \\
\hline Myocardial infarction & $0(0.0 \%)$ \\
\hline Acute kidney injury & $0(0.0 \%)$ \\
\hline Coronary obstruction requiring interv. & $0(0.0 \%)$ \\
\hline Major vascular complication & $0(0.0 \%)$ \\
\hline Life-threatening bleeding & $1(7.7 \%)$ \\
\hline $\begin{array}{l}\text { Hospitalisation for valve-related symptoms or } \\
\text { congestive heart failure }\end{array}$ & $1(7.7 \%)$ \\
\hline Valve-related dysfunction requiring repeat procedure & $1(7.7 \%)$ \\
\hline Pacemaker implant & $3(23.1 \%)$ \\
\hline
\end{tabular}

Data are displayed as $\mathrm{n}(\%)$. *VARC-2: composite of all-cause mortality, all stroke (disabling and non-disabling), life-threatening bleeding, acute kidney injury stage 2 or 3 (including renal replacement therapy),

coronary obstruction requiring intervention, major vascular complication, valve-related dysfunction requiring repeat procedure.

"VARC-1: composite of all-cause mortality, major stroke, life-threatening bleeding, acute kidney injury stage 3 , periprocedural myocardial

infarction, major vascular complications and repeat procedure for

valve-related dysfunction. VARC: Valve Academic Research Consortium

While the mean logistic EuroSCORE of $14.4 \pm 3.7 \%$ and the mean STS PROM score of $4.3 \pm 1.6 \%$ are rather indicative for an intermediate to high-risk population, based on comorbidities the Heart Team judged each patient as high risk. The average age was $83.3 \pm 6.3$ years, all patients were in NYHA Class III, all but one patient had chronic kidney disease stage 2 or 3 , and three quarters of patients were classified in ASA class 3 (severe systemic disease).

In two patients it was recognised during the procedure that the implantation of a self-expanding valve might not lead to an optimal result. Both patients had a horizontal aorta (one with additionally short aorta ascendens and narrow aortic arch). Despite several implantation attempts, the stent could not be anchored in a coaxial position in relation to the horizontal aortic anatomy due to intense flaring of the inflow portion of the frame. Since completere-sheathing

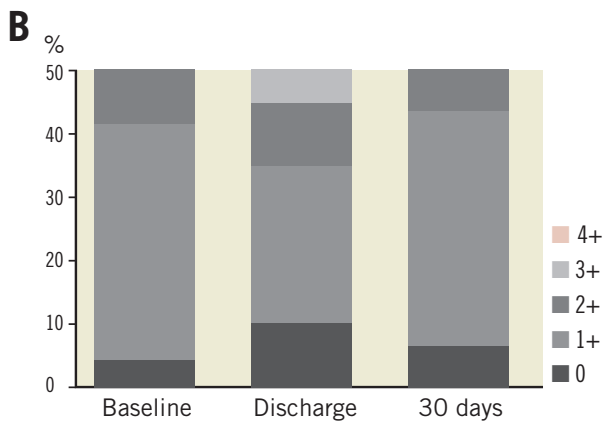

Figure 5. Echocardiographic parameters from baseline to 30 days. A) Mean gradient and EOA. B) Total aortic regurgitation according to 4-point scale. EOA: effective orifice area 
allows for safe and easy removal, it was decided to treat the patient with a balloon-expandable valve instead. The BIOVALVE was successfully retrieved in both cases without any complications, and both patients were treated with a balloon-expandable valve.

Overall, re-sheathing was performed in five patients and facilitated repositioning and placement of the prosthesis. Notably, since BIOVALVE-I is a first-in-human experience, it was tempting to use the re-sheathing function to ensure an optimal position. Thereby, the number of patients with re-sheathing is within the range reported for other first-in-human series such as that of Willson et $\mathrm{al}^{10}$ with re-sheathing being done in four out of 10 patients. In our series, re-sheathing and repositioning did not lead to stroke or any other embolic complication. Also, for this phase of the trial, it was recommended to use fast pacing to place the prosthesis. In two patients the implantation was performed without fast pacing, showing that this is a feasible option.

Post-dilatation was performed in nine cases in an attempt to optimise the outcome, and provided improvement in aortic valve competency in all but two cases. In one patient, intraoperative severe paravalvular aortic regurgitation could not be resolved after postdilatation. The underlying cause could not be fully explained. The prosthesis was placed at the intended position but potentially heavy eccentric calcification in combination with an oval annulus might have influenced the outcome. The patient was successfully treated with a $26 \mathrm{~mm}$ balloon-expandable valve within the BIOVALVE with good haemodynamic results and an uneventful follow-up.

\section{0-DAY FOLLOW-UP}

Echocardiographic parameters showed a large EOA of $1.8 \pm 0.3 \mathrm{~cm}^{2}$, an EOA Index of $1.1 \pm 0.2 \mathrm{~cm}^{2} / \mathrm{m}^{2}$, and a low mean gradient of $6.7 \pm 2.3 \mathrm{mmHg}$. Moderate paravalvular leak at 30 days was observed in one patient. While the rate of moderate regurgitation is within the range of the CoreValve prosthesis ${ }^{9-12}$, it is scientifically proven that any moderate paravalvular leak should be avoided ${ }^{12,13}$. Hereby, it is worth mentioning that we observed an improvement of regurgitation from discharge to 30 days in three patients which could be explained by the mechanical properties of the nitinol stent.

Three pacemakers were implanted (23.1\%), including one due to an AV block which occurred before valve placement. While a lower rate of pacemakers and LBBB would have been desirable, the values are still within the range of self-expanding prostheses ${ }^{11,12,14,15}$. It remains to be seen if the implant depth influences the rate of conduction disturbances leading to pacemaker implantation as observed in other series ${ }^{9,12,14,15}$.

To summarise, an inherent limitation for a first-in-human study is the small sample size, which allows determination of feasibility and assessment of safety, but hampers comparison with outcomes from other studies. So far, limited conclusions on the performance of the device and on the specific claims of the device can be drawn. Certainly, re-sheathing has proven to be functional. The device is easy to handle and valve implantation provides a good level of control, but it does not seem suitable for all aortic anatomies. While the rate of paravalvular leakage is slightly higher than expected and requires further investigation in a larger patient population, it is, as detailed above, still within the range of other self-expanding valves.

Nevertheless, it is encouraging that: (a) no death and no stroke occurred; (b) the values and complication rates are within the range or even lower than the pooled estimates of VARC-related event rates established by Genereux et $\mathrm{al}^{16}$, as well as those of other published studies with self-expanding valves ${ }^{9-12}$; (c) no vascular complication occurred despite the use of an $18 \mathrm{Fr}$ sheath; and (d) no acute kidney injury occurred despite the high incidence of renal insufficiency at baseline.

\section{Conclusion}

In this first-in-human study, the feasibility and safety of the BIOVALVE system could be demonstrated. Valve implantation provides a good level of control including loading and re-sheathing functionality. Low complication rates at 30 days were observed. Assessments in a larger patient population with longer follow-up will be needed to demonstrate further the usefulness and performance of the device.

\section{Impact on daily practice}

The BIOVALVE-I study presents the safety and performance outcomes of a novel self-expanding transcatheter aortic heart valve with special features such as ease of use and re-sheathing functionality. Proof of concept has been provided with low complication rates at 30-day follow-up.

\section{Acknowledgements}

We thank Ralf Birkemeyer, MD, Ralph Toelg, MD, Lutz Buellesfeld, MD, Steffen Schneider, PhD, all members of the data monitoring committee, Ron Waksman, MD (chairman) and Stephan Windecker, $\mathrm{MD}, \mathrm{PhD}$, who, together with the two principal investigators, constituted the steering committee and Beatrix Doerr, consultant medical writer, who provided medical writing services.

\section{Funding}

The study was sponsored by Biotronik AG, Bülach, Switzerland.

\section{Conflict of interest statement}

The authors have no conflicts of interest to declare.

\section{References}

1. Joint Task Force on the Management of Valvular Heart Disease of the European Society of Cardiology (ESC); European Association for Cardio-Thoracic Surgery (EACTS), Vahanian A, Alfieri O, Andreotti F, Antunes MJ, Barón-Esquivias G, Baumgartner H, Borger MA, Carrel TP, De Bonis M, Evangelista A, Falk V, Iung B, Lancellotti P, Pierard L, Price S, Schäfers HJ, Schuler G, Stepinska J, Swedberg K, Takkenberg J, Von Oppell UO, Windecker S, Zamorano JL, Zembala M. Guidelines on the management of valvular heart disease (version 2012). Eur Heart J. 2012;33:2451-96 
2. Iung B, Cachier A, Baron G, Messika-Zeitoun D, Delahaye F, Tornos P, Gohlke-Bärwolf C, Boersma E, Ravaud P, Vahanian A. Decision-making in elderly patients with severe aortic stenosis: why are so many denied surgery? Eur Heart J. 2005;26:2714-20.

3. Cribier A. Development of transcatheter aortic valve implantation (TAVI): a 20-year odyssey. Arch Cardiovasc Dis. 2012;105: 146-52.

4. Neragi-Miandoab S, Skripochnik E, Salemi A, Girardi L. Recently patented transcatheter aortic valves in clinical trials. Recent Pat Cardiovasc Drug Discov. 2013;8:186-91.

5. Tchetche D, Van Mieghem NM. New-generation TAVI devices: description and specifications. EuroIntervention. 2014;10 Suppl U:U90-100.

6. Kappetein AP, Head SJ, Généreux P, Piazza N, van Mieghem NM, Blackstone EH, Brott TG, Cohen DJ, Cutlip DE, van Es GA, Hahn RT, Kirtane AJ, Krucoff MW, Kodali S, Mack MJ, Mehran R, Rodés-Cabau J, Vranckx P, Webb JG, Windecker S, Serruys PW, Leon MB; Valve Academic Research Consortium-2. Updated standardized endpoint definitions for transcatheter aortic valve implantation: the Valve Academic Research Consortium-2 consensus document. EuroIntervention. 2012;8:782-95.

7. Leon MB, Piazza N, Nikolsky E, Blackstone EH, Cutlip DE, Kappetein AP, Krucoff MW, Mack M, Mehran R, Miller C, Morel MA, Petersen J, Popma JJ, Takkenberg JJ, Vahanian A, van Es GA, Vranckx P, Webb JG, Windecker S, Serruys PW. Standardized endpoint definitions for transcatheter aortic valve implantation clinical trials: a consensus report from the Valve Academic Research Consortium. Eur Heart J. 2011;32:205-17.

8. Hahn RT, Pibarot P, Weissman NJ, Rodriguez L, Jaber WA. Assessment of paravalvular aortic regurgitation after transcatheter aortic valve replacement: intra-core laboratory variability. J Am Soc Echocardiogr. 2015;28:415-22.

9. Neragi-Miandoab S, Salemi A. The most relevant complications of transcatheter aortic valve implantation according to VARC criteria. Minerva Cardioangiol. 2014;62:205-20.

10. Willson AB, Rodès-Cabau J, Wood DA, Leipsic J, Cheung A, Toggweiler S, Binder RK, Freeman M, DeLarochellière R, Moss R, Nombela-Franco L, Dumont E, Szummer K, Fontana GP, Makkar R, Webb JG. Transcatheter aortic valve replacement with the St. Jude Medical Portico valve: first-in-human experience. J Am Coll Cardiol. 2012;60:581-6.

11. Adams DH, Popma JJ, Reardon MJ, Yakubov SJ, Coselli JS, Deeb GM, Gleason TG, Buchbinder M, Hermiller J Jr, Kleiman NS, Chetcuti S, Heiser J, Merhi W, Zorn G, Tadros P, Robinson N, Petrossian G, Hughes GC, Harrison JK, Conte J, Maini B, Mumtaz M, Chenoweth S, Oh JK; U.S. CoreValve Clinical
Investigators. Transcatheter aortic-valve replacement with a selfexpanding prosthesis. N Engl J Med. 2014;370:1790-8.

12. Linke A, Wenaweser P, Gerckens U, Tamburino C, Bosmans J, Bleiziffer S, Blackman D, Schäfer U, Müller R, Sievert H, Søndergaard L, Klugmann S, Hoffmann R, Tchétché D, Colombo A, Legrand VM, Bedogni F, lePrince P, Schuler G, Mazzitelli D, Eftychiou C, Frerker C, Boekstegers P, Windecker S, Mohr FW, Woitek F, Lange R, Bauernschmitt R, Brecker S; ADVANCE study Investigators. Treatment of aortic stenosis with a self-expanding transcatheter valve: the International Multi-centre ADVANCE Study. Eur Heart J. 2014;35:2672-84.

13. Mack MJ, Leon MB, Smith CR, Miller DC, Moses JW, Tuzcu EM, Webb JG, Douglas PS, Anderson WN, Blackstone EH, Kodali SK, Makkar RR, Fontana GP, Kapadia S, Bavaria J, Hahn RT, Thourani VH, Babaliaros V, Pichard A, Herrmann HC, Brown DL, Williams M, Davidson MJ, Svensson LG; PARTNER 1 trial investigators, Akin J. 5-year outcomes of transcatheter aortic valve replacement or surgical aortic valve replacement for high surgical risk patients with aortic stenosis (PARTNER 1): a randomised controlled trial. Lancet. 2015 Mar 15. [Epub ahead of print].

14. Lenders GD, Collas V, Hernandez JM, Legrand V, Danenberg HD, den Heijer P, Rodrigus IE, Paelinck BP, Vrints CJ, Bosmans JM. Depth of valve implantation, conduction disturbances and pacemaker implantation with CoreValve and CoreValve Accutrak system for Transcatheter Aortic Valve Implantation, a multi-center study. Int J Cardiol. 2014;176:771-5.

15. van der Boon RM, Houthuizen P, Urena M, Poels TT, van Mieghem NM, Brueren GR, Altintas S, Nuis RJ, Serruys PW, van Garsse LA, van Domburg RT, Cabau JR, de Jaegere PP, Prinzen FW. Trends in the occurrence of new conduction abnormalities after transcatheter aortic valve implantation. Catheter Cardiovasc Interv. 2015;85:144-52.

16. Généreux P, Head SJ, Van Mieghem NM, Kodali S, Kirtane AJ, Xu K, Smith C, Serruys PW, Kappetein AP, Leon MB. Clinical outcomes after transcatheter aortic valve replacement using valve academic research consortium definitions: a weighted meta-analysis of 3,519 patients from 16 studies. J Am Coll Cardiol. 2012;59:2317-26.

\section{Supplementary data}

Moving image 1. Re-sheathing of the BIOVALVE prosthesis.

Moving image 2. Implantation of the BIOVALVE prosthesis.

The supplementary data are published online at: http://www.pcronline.com/

eurointervention/90th_issue/160 